\title{
Clinical and radiological findings of pulmonary manifestation of rheumatoid arthritis
}

\author{
Dheeraj Kumar ${ }^{1 *}$, Vijay Achari ${ }^{2}$
}

${ }^{1}$ Senior Residence, ${ }^{2}$ Professor, Department of Medicine, Patna Medical College and Hospital, Patna, Bihar, INDIA. Email: dheeraj.vision@gmail.com

Abstract Background: Rheumatoid arthritis is a long-term autoimmune disorder that primarily affects joints. It typically results in warm, swollen, and painful joints. Pain and stiffness often worsen following rest. Most commonly, the wrist and hands are involved, with the same joints typically involved on both sides of the body. The disease may also affect other parts of the body. Methodology: The patients were examined thoroughly emphasis was given on clinical, radiological, PFT and HRCT studies along plural fluid analysis in patients having pleural effusion. The prospective study included 50 patients with RA met the American collage of rheumatology classification criteria for RA. Study conducted in the department of General Medicine in Patna Medical College during the period of March 2018 to January 2019. Results: Several study results indicate that pulmonary complications are more common in men, our study findings indicated an overall predominance (1.38:1) of men, which was mainly due to a predominance of male number in our study. The most common symptom we observed among the study subjects is chough with sputum, followed by cough, wheezing with dyspnoea, sputum, wheez and dyspnoea. Pleural diffusion was observed in $8(16 \%)$ patients. Conclusion: The pulmonary changes may be accompanied as a systemic component of the RA. If these changes are well recognised, they can help in the diagnosis of the RA.

*Address for Correspondence:

Dr Dheeraj Kumar, Senior Residence, Department of Medicine, Patna Medical College and Hospital, Patna, Bihar, INDIA.

Email: dheeraj.vision@gmail.com

Received Date: 25/12/2019 Revised Date: 09/01/2020 Accepted Date: 02/02/2020

DOI: https://doi.org/10.26611/10211634

This work is licensed under a Creative Commons Attribution-NonCommercial 4.0 International License. $(\mathrm{cc})$ EY-NC

\begin{tabular}{|l|l|}
\hline \multicolumn{2}{|c|}{ Access this article online } \\
\hline Quick Response Code: & Website: \\
\hline & www.medpulse.in \\
\cline { 2 - 2 } & \\
\hline
\end{tabular}

\section{INTRODUCTION}

The first known traces of arthritis date back at least as far as $4500 \mathrm{BC}$. A text dated $123 \mathrm{AD}$ first describes symptoms very similar to RA. It was noted in skeletal remains of Native Americans found in Tennessee. ${ }^{1}$ In Europe, the disease is vanishingly rare before the 17 th century. ${ }^{2}$ The first recognized description of RA in modern medicine was in 1800 by the French physician Dr Augustin Jacob Landré-Beauvais (1772-1840) who was based in the famed Salpêtrière Hospital in Paris. ${ }^{3}$ The name "rheumatoid arthritis" itself was coined in 1859 by British rheumatologist Dr Alfred Baring Garrod. ${ }^{4}$ The art of Peter Paul Rubens may possibly depict the effects of RA. In his later paintings, his rendered hands show, in the opinion of some physicians, increasing deformity consistent with the symptoms of the disease. ${ }^{5,6} \mathrm{RA}$ appears to some to have been depicted in 16th-century paintings. ${ }^{7}$ However, it is generally recognized in art historical circles that the painting of hands in the 16th and 17th century followed certain stylized conventions, most clearly seen in the Mannerist movement. It was conventional, for instance, to show the upheld right hand of Christ in what now appears a deformed posture. These conventions are easily misinterpreted as portrayals of disease. Historic treatments for RA have also included: rest, ice, compression and elevation, apple diet, nutmeg, some light exercise every now and then, nettles, bee venom, copper bracelets, rhubarb diet, extractions of teeth, fasting, honey, vitamins, insulin, magnets, and electroconvulsive therapy $(\mathrm{ECT})^{8}$ RA primarily starts as a state of persistent cellular activation leading to autoimmunity and immune complexes in joints and other organs where it manifests. 
The initial site of disease is the synovial membrane, where swelling and congestion lead to infiltration by immune cells. Three phases of progression of RA are an initiation phase (due to non-specific inflammation), an amplification phase (due to $T$ cell activation), and chronic inflammatory phase, with tissue injury resulting from the cytokines, IL1, TNF-alpha and IL-6. ${ }^{9}$ People with RA have an eight times higher risk of developing lung disease compared to the rest of the population. In people who have RA, specific factors may increase their risk of the lungs being affected. Anti-CCP antibodies are a type of protein that is produced by the immune system. Testing positive for anti-CCP antibodies is one indicator of RA. High levels may indicate the severity of the disease.

The following groups have additional risk factors for developing rheumatoid lung disease:

- men

- people who smoke, especially men

- people over 60 years of age who have been diagnosed with RA

There are a variety of possible lung issues associated with rheumatoid lung disease. The depending on the severity and type of lung complication. People who develop RArelated scarring and interstitial lung disease often have a poor prognosis. People who have RA are not always able to prevent rheumatoid lung disease. But some can reduce their risk by not smoking and by getting regular checkups to monitor breathing and check for lung problems. When a doctor can diagnose rheumatoid lung disease early, it may be easier to treat.

\section{METHODOLOGY}

It was prospective study The patients were examined thoroughly emphasis was given on clinical, radiological, PFT and HRCT studies along plural fluid analysis in patients having pleural effusion. Patna Medical College and Hospital, in the department of Medicine. Period(March 2018 to January 2019)
a. Preparatory phase- 2 month
b. Phase of data collection- 08 months
c. Phase of data analysis-04 months
d. Report writing and submission-04 months

The study was conducted among those patients who were suffering from pulmonary diseases arising from Rheumatoid Arthritis.

Inclusion criteria:

Patients with diagnosed RA attending MOPD and Rheumatology OPD.

Exclusion criteria:

Exclusion from enrolment was;

- Smokers

- ILD related to Pneumoconiosis.
- $\mathrm{H} / \mathrm{O}$ tuberculosis

- Any other cause of ILD other than RA.

The prospective study included 50 patients with RA met the American collage of rheumatology classification criteria for RA ${ }^{118}$. The patient referred from Rheumatology Outpatient Clinic at Patna Medical College and Hospital.

Study procedure (Methodology):

The patients who met the American College of Rheumatology Criteria were further referred for pulmonary evaluation. They were subjected to clinical examination of chest, X-Ray-chest (CXR), pulmonary function tests (PFT) and high resonance computed tomography (HRCT). Signs and symptoms were recorded from each patient based on a set of questionnaires focusing on cough, sputum production, wheezing and dyspnoea. History of smoking was also recorded and they were excluded.

Laboratory investigation:

Rheumatoid factor (RF), C-reactive protein (CRP) and erythrocyte sedimentation rate (ESR) and Plural fluid analysis (Sugar, Protein, LDH) were performed. Informed consent was obtained from the participants.

Pulmonary function tests (PFTs)

Tests were performed via spirometry, the results were recorded, the values and percentages of forced vital capacity (FVC) measured when the patient is exhaling with maximal speed and effort and forced expiratory volume during the first second of FVC (FEV1) were measured. Pulmonary function test abnormalities were categorized as abnormal if values were less than $80 \%$ of the predicted values adjusted for age, sex, and height. Obstruction was defined by a FEV1/FVC ratio less than or equal to $80 \%$ of the predicted ratio. Obstruction disorders are classified according to $\mathrm{FEV1/FVC} \mathrm{ratio} \mathrm{results} \mathrm{to,} \mathrm{mild} \mathrm{obstruction}$ (ratio: 61-80\%), moderate obstruction (45-60\%), and severe obstruction $(<45 \%)$. Restriction was defined as FVC less than $80 \%$ of predicted with a normal FEV1/FVC ratio. Restriction disorders are classified according to $\mathrm{FVC}$ to mild restriction (FVC: $66-80 \%$ ), moderate restriction $(50-65 \%)$, and severe restriction $(<50 \%)$, A combined pattern defined as coexistence of airway obstruction and restrictive syndrome.

\section{RESULTS}

\begin{tabular}{ccc}
\multicolumn{3}{c}{ Table: 1: Age Distribution } \\
\hline Age in Year & No of Cases & Percentage \\
\hline$<30$ Years & 06 & 12 \\
$31-40$ Years & 09 & 18 \\
$41-50$ Years & 18 & 36 \\
$51-60$ Years & 12 & 24 \\
$>60$ Years & 05 & 10 \\
\hline Total & 50 & 100
\end{tabular}


Distribution of study subjects according to age is mentioned in Table 1. The most common age group affected by rheumatoid arthritis was $41-50$ years account for $36 \%$ (18) patients, followed by 51-60 years consisting $24 \%$ (12) patients and 31-40 years age group involving $18 \%$ patients. The least common age group of our study was $>60$ years accounts for $10 \%$ (5) patients followed by $<30$ years accounts for $12 \%(6)$ patients.

\begin{tabular}{ccc}
\multicolumn{3}{c}{ Table: 2: Sex Distribution } \\
\hline Sex & No of Cases & Percentage \\
\hline Male & 21 & 42 \\
Female & 29 & 58 \\
\hline Total & 50 & 100
\end{tabular}

Sex distribution of subjects studied is mentioned in Table 2. We found a slight predominance in our study as 58\% (29) patients of our study participants were male and $42 \%$ (21) were female. The male to female ratio of our study participants was 1.38:1.

Table 3: Duration of the disease

\begin{tabular}{ccc}
\hline Duration of years & No of Cases & Percentage \\
\hline$<05$ Years & 09 & 18 \\
$5-10$ Years & 17 & 34 \\
$>11$ Years & 24 & 48 \\
\hline Total & 50 & 100 \\
\hline
\end{tabular}

Duration of symptoms among the study subjects is mentioned in Table 3. Regarding duration of rheumatoid arthritis, majority of the patients i.e. $32(50.8 \%)$ patients had disease for $>11$ years. Next were $34 \%$ (17) patients who had a history of disease from 5-10 years. And 18\% patients had a history of disease $<5$ years.

Table 3: Normal and abnormal Findings of pulmonary function test

\begin{tabular}{ccc}
\hline PFT & No of Cases & Percentage \\
\hline Normal & 20 & 40 \\
Abnormal & 30 & 60
\end{tabular}

Table 3 shows the PFT finding of the study participants. Majority of patients of our study, i.e. $30(60 \%)$ showed an abnormal PFT finding and $20(40 \%)$ patients showed normal PFT finding.

Table: 4: Patient characteristic according to the presence of any pulmonary function abnormalities

\begin{tabular}{cccc}
\hline Any symptoms & $\begin{array}{c}\text { Normal PFT } \\
(\mathrm{n}=20)\end{array}$ & $\begin{array}{c}\text { Abnormal PFT } \\
(\mathrm{n}=30)\end{array}$ & Total \\
\hline Cough & $4(20 \%)$ & $6(20 \%)$ & 10 \\
Sputum & $2(10 \%)$ & $6(20 \%)$ & 08 \\
Wheezing & $3(15 \%)$ & $4(13.3 \%)$ & 07 \\
Dyspnoea & $2(10 \%)$ & $3(10 \%)$ & 05 \\
Cough and Sputum & $5(25 \%)$ & $6(20 \%)$ & 11 \\
Wheezing and Dyspnoea & $4(20 \%)$ & $5(16 \%)$ & 09 \\
\hline Total & $20(100 \%)$ & $30(100 \%)$ & 50 \\
\hline
\end{tabular}

Patient characteristic according to the presence of any pulmonary function abnormalities is mentioned in Table
4. As we mentioned earlier $11(22 \%)$ patients were presented with the symptom of cough with sputum, among them $6(20 \%)$ showed abnormal PFT finding and 5 (25) showed normal PFT finding. Cough was present in 10 (20\%) patients among them 6 had abnormal PFT finding. Whhezing was observed among 7 (14\%) patients among them $4(13.3 \%)$ had abnormal PFT finding. Among the 9 (18\%) patients who had dyspnoea 5 (16\%) showed abnormal PFT finding.

Table 5: Patient characteristic of X-Ray chest among RA patient

\begin{tabular}{ccc}
\hline X-ray findings & No of Cases & Percentage \\
\hline Normal & 33 & 66 \\
B/L Lower zone haziness & 12 & 24 \\
Prominent Pulmonary vasculature & 05 & 10
\end{tabular}

Chest X-ray findings of the study subjects is mentioned in Table 5. We observed normal chest $X$-ray findings in majority of patients i.e. $66 \%$ (33) patients. Bilateral lower zone haziness was observed among $24 \%$ (12) patients and $10 \%$ (5) showed prominent pulmonary vasculature.

Table: 6: Mean and SD value of Sugar, Protein, LDH of pleural fluid among those patients who were Plural effusion present

\begin{tabular}{ccc}
\hline Biochemical analysis & \multicolumn{2}{c}{ Plural fluid } \\
\cline { 2 - 3 } & Mean & SD \\
\hline Sugar & 45.428 & 5.56 \\
Protein & 1.617 & $\mathbf{0 . 2 1}$ \\
LDH & $\mathbf{2 1 0 . 8 5 7}$ & 13.70 \\
\hline
\end{tabular}

The biochemical findings of the patients who were presented with pleural effusion is mentioned in Table 6. The mean and value of sugar in pleural fluid was 45.428 \pm 5.56 . The man Protein level in pleural fluid was $1.617 \pm 0.21$ and the mean LDH level of pleural fluid was $210.857 \pm 13.70$.

Table 7 shows the correlation between HRCT findings and respiratory symptoms in Rheumatoid Arthritis patients. In our study $32(64 \%)$ patients showed an abnormal HRCT finding among them 27 (54\%) patients had respiratory symptom and other $5(10 \%)$ had no respiratory symptoms. HRCT finding showed decreased attenuation in 14 (28\%) patients among them only 2 patient had no respiratory symptoms. In HRCT finding, bronchiectasis was observed in $11(22 \%)$ patients among them $10(37.03 \%)$ were presented with respiratory symptom and 1 patient was presented without any respiratory symptom. HRCT showed air trapping was observed in $6(12 \%)$ patients; 5 had respiratory symptom and 1 had no respiratory symptom. Reticulo-nodular pattern, pulmonary nodules ground glass opacity and pleural effusion was observed in 14\% (7), 6\% (3), 10\% (5) patients respectively in HRCT finding, and all of them had respiratory symptoms. Pleural Effusion was observed in 16\% (8) patients out of them 6 had respiratory symptom. 
Table: 7: Correlation of HRCT findings and respiratory symptoms in Rheumatoid Arthritis patients

\begin{tabular}{ccccc}
\hline HRCTfindings & No of cases & Percentage & Respiratory symptomatic & Respiratory asymptomatic \\
\hline Abnormal & 32 & 64 & $24(48 \%)$ & $8(16 \%)$ \\
a) Decreased attenuation & 14 & 28 & $12(44.4 \%)$ & $2(40 \%)$ \\
b) Bronchiectasis & 11 & 22 & $10(37.03 \%)$ & $2(20 \%)$ \\
c) Bronchial wall thickening & 9 & 18 & $7(25.92 \%)$ & 0 \\
d) Reticulo-nodular pattern & 7 & 14 & $7(25.92 \%)$ & $1(20 \%)$ \\
e) Air trapping & 6 & 12 & $5(18.51 \%)$ & 0 \\
f) Pulmonary nodules & 3 & 6 & $3(11.1 \%)$ & 0 \\
g) Ground glass opacities & 5 & 10 & $5(18.51 \%)$ & $2(40 \%)$ \\
h) Pleural effusion & 8 & 16 & $6(22.2 \%)$ & $3(6 \%)$ \\
Normal & 18 & 36 & $15(30 \%)$ & \\
\hline
\end{tabular}

\section{DISCUSSION}

In our study the most of the patients aged below 50 years. Age ranged varied from $<30$ years to $>60$ years. This observation was quite similar with a similar study done by S Raniga et al., ${ }^{[10]}$ where the average age of male and female patients was 48.4 years and 45.8 years respectively. In the study by Hoda Mahmoud Abd El-Wahab et al.,${ }^{11}$ the age ranged between 25 to 70 years with a mean age of 47.5 years which was quite consistent with our study. We found male are more likely affected by pulmonary disease arising from RA compared to women. In our study we observed a male to female ratio was 1.38:1. This observation is in contrary with many studies. A study by Hoda Mahmoud Abd El-Wahab et al. ${ }^{11}$ in a similar study showed that the male to female ration in their study was 1:5. This was consistent with the study done by N. Fatima et al., ${ }^{12}$ they showed RA predominantly occurs in females with women suffering $3-5$ times more than males. This study also revealed a much higher incidence rate (Female: male ratio $3: 1)$ among females. The variation in the level of sex hormones of females (oestrogen and progesterone, which regulate the inflammatory process) is the main cause of development of RA among them. ${ }^{13}$ In a study by N. Fatima et al., ${ }^{12}$ majority of RA patients had a restrictive pattern on pulmonary function testing which again highlights the presence of lung fibrosis and an underlying interstitial lung disease. ${ }^{14} 8 \%$ of our RA cases had obstructive pattern with airflow obstruction that was most marked when respiratory volumes were low and trapping of air occurred. Hoda Mahmoud Abd El-Wahab et al. ${ }^{11}$ in their study showed twenty (66.6\%) patients had some PFT result abnormalities. Restrictive lung disease was in $12(75 \%)$, obstructive lung disease in 5(25\%) and mixed disorders in $2(15 \%)$. These results were similar to Bilgici et al.. ${ }^{[15]}$ who reported abnormal PFT results in (55.8\%) of their study group. The predominant presentation on X-ray Chest was a bilateral lower zone diffuse shadow (24\%) predominantly, reticular and nodular pattern and prominent pulmonary vasculature. These findings are suggestive of an underlying interstitial lung disease. Also, prominent pulmonary vasculature $(10 \%)$ could be due to pulmonary vasculitis which is a less common pulmonary manifestation of RA. HRCT findings of our study showed that 32 patients had an abnormal HRTC finding out of them 24 were symptomatic and rest of the 8 were asymptomatic. The most common HRCT finding was Decreased attenuation (14), followed by Bronchiectasis (11), Bronchial wall thickening (9), Reticulo-nodular pattern (7), Air trapping (6), Ground glass opacities (5), Pulmonary nodules (3) and pleural effusion (8). This observation was quite in a agreement with a study by Sandipan Banik et al.. ${ }^{[16]}$ In their study decreased attenuation is the most common HRCT abnormality. Plotting the abnormality against age and duration of RA, there was correlation with both $(p<0.00)$. Second most frequent finding was bronchiectasis; when adjusted with smoking and duration of disease, no significant associations were found. But there was significant correlation between bronchiectasis and increased duration of disease $(p=0.011)$. Bronchial wall thickening in HRCT thorax is usually found after long standing airway inflammation; so it was plotted against age $(\mathrm{p}<0.001)$ and duration of disease $(\mathrm{p}=0.024)$ and in both cases found to be significant. Pleural effusion showed a significant correlation with disease duration $(\mathrm{p}=0.022)$. Reticulonodular shadows and ground-glass opacities when found in HRCT indicates interstitial involvement. It showed positive correlation with the disease duration $(\mathrm{p}<0.001$ for reticulo-nodular shadows and $\mathrm{p}=0.006$ for ground-glass opacities). In study by Hoda Mahmoud Abd El-Wahab et al., ${ }^{[11]}$ the common CT findings were Ground Glass Opacity $(66.6 \%)$, reticulation $(36.6 \%)$, nodules (26.6\%), honeycombing (20\%), plural thickening and effusion (10\%), Bronchiectasis (33.3\%). Tanaka et al.. ${ }^{17}$ also reported Ground Glass Opacity was the most frequent finding in their study (90\%), and the previously mentioned study by Skare et al..$^{[18]}$ (39\%). In addition Akira et al. ${ }^{19}$ reported that reticulation was the most frequent finding in the study as (72\%). In our study, patient's age and duration of disease were found to be predictive factors of CT findings for lung involvement. This consistent with some studies that have noted correlation between age and lung 
involvement Johkoh and Muller and Woodhead et al. ${ }^{20,21}$ found no correlation between higher levels of RF and abnormal CT. We agree with this result, disagree with the study done by Zrour et al..$^{22}$ and Bilgici et al. ${ }^{15}$ that detected correlation between higher level of RF and abnormal CT finding. CT scanning increases the detection of the pulmonary rheumatoid nodules. These nodules may be single or multiple, varying in size from (0.5) $\mathrm{mm}$ up to (7) $\mathrm{cm}$ in diameter. They exist in the middle and upper zones of lung and tend to be peripheral Helmers et al. ${ }^{23}$, the central necrosis may occur in some of pulmonary nodules and called as rheumatoid necrobiotic nodules. Up to $50 \%$ will cavitate. Radiologically, rheumatoid nodules are nonspecific and differential diagnosis includes malignancy, infection and vasculitides. In a study by Sandipan Banik et al. ${ }^{16}$ about $24 \%$ of all patients showed pleural disease on HRCT. Pleural effusion was found in $35.71 \%$ and pleural thickening in $17.85 \%$. Among patients having pleural effusion all $(\mathrm{n}=10)$ were symptomatic. In a Greek study by Metafratzi ZM et al.., and another study by Helmers R et al.., ${ }^{23}$ pleural thickening and effusion were observed in a frequency, which is slightly lower than our values. However, this relatively higher prevalence of pleural effusion can be explained by the fact that pleural effusion occurs early in the disease and affect more the middle aged patients, as found by KA Stanek and KA Mills. So, from this present study some facts about the clinical course, factors and effects of RA regarding its pulmonary affections are quite evident: RA manifestations are found in relatively younger population and majority of patients are respiratory symptomatic.

\section{CONCLUSION}

Most of the pulmonary manifestations of RA are usually related to the duration of RA and age of the patient, with exception of pleural effusion, which is more prevalent early in the disease. Respiratory symptoms and PFT abnormalities can be used as predictors of lung disease. To provide optimal treatment. The pulmonary changes may be accompanied as a systemic component of the RA. If these changes are well recognised, they can help in the diagnosis of the RA. Sings of pluropulmonary diseases that appear on HRCT with RA, are the result of airway or lung parenchymal involvement. With its $3 \mathrm{~d}$ images it allows assessment not only for individual lung but also lung segments it proves to be very sensitive and accurate modality to diagnosis and classify different patterns of these changes even in asymptomatic and/or normal PFT.

\section{REFERENCES}

1. Rothschild, Bruce M. "Tennessee Origins of Rheumatoid Arthritis". Mcclungmuseum.utk.edu. Archived from the original on February 2, 2012. Retrieved March 3, 2011.
2. "Bones of contention". Arthritis Research UK. April 1999. Archived from the original on February 19, 2003. Retrieved February 5, 2013.

3. "Rheumatoid Arthritis and Complementary Health Approaches". National Center for Complementary and Integrative Health. January 2006. Archived from the original on July 5, 2015. Retrieved July 1, 2015.

4. Rothschild BM, Rothschild C, Helbling M (October 2003). "Unified theory of the origins of erosive arthritis: conditioning as a protective/directing mechanism?". The Journal of Rheumatology. 30 (10): 2095-102.

5. Appelboom T, de Boelpaepe C, Ehrlich GE, Famaey JP (February 1981). "Rubens and the question of antiquity of rheumatoid arthritis". JAMA. 245 (5): 483-6.

6. Kelly, Janis (14 June 2005). "Did RA travel from New World to Old? The Rubens connection". Medscape. Archivedfrom the original on 15 December 2013. Retrieved March 3,2011.

7. Dequeker J, Rico H (July 1992). "Rheumatoid arthritis-like deformities in an early 16th-century painting of the FlemishDutch school". JAMA. 268 (2): 249-51.

8. Hart FD (March 1976). "History of the treatment of rheumatoid arthritis". British Medical Journal. 1 (6012): 763-5.

9. Shah, Ankur (2012). Harrison's Principles of Internal Medicine (18th ed.). United States: McGraw Hill. p. 2738.

10. Raniga et al. Interstitial Lung Disease (Ild) In Rheumatoid Arthritis (Ra)"A Study Of Thirty Cases; IJRI, 16:4, November 2006, pp: 835- 839

11. Hoda Mahmoud Abd El-Wahab et al. Hrct Extra-Articular Pleuropulmonary Findings In Rheumatoid Arthritis; AlAzhar Assiut Medical Journal Vol 13, No 2 , April 2015 Suppl; page: 64-70.

12. N. Fatima et al. A Study on the Pulmonary Manifestations of Rheumatoid Arthritis from a North Indian Town; Open Journal of Respiratory Diseases, 2013, 3, 128-131.

13. L. M. Pamell, C. L. Galligon and C. N. Fish, "Sex Affects Immunity Autoimmune," 2012.

14. Yuksekkaya R, Celikyay F, Yilmaz A, Arslan S, Inanir A, Inonu H, Deniz C. Pulmonary involvement in rheumatoid arthritis: multidetector computed tomography findings. Acta Radiologica, 2013; 54(10):1138-4.

15. Bilgici A, Ulusony $\mathrm{H}$, Kura $\mathrm{O}$, et al.. Pulmonary involvement in rheumatoid arthritis. Rheumatol Int, 2005; 25:429-435

16. Sandipan Banik, Sumit Roy Tapadar, Aniruddha Ray , Arunabha Datta Chaudhuri, "A Study on Pulmonary Manifestations of Rheumatoid Arthritis" Journal of Clinical and Diagnostic Research. 2018 Jun, Vol-12(6): OC05OC09.

17. Tanaka N, Kim JS, Newell JD, Brown KK, Cool CD, Meehan R, Emoto T, Matsumoto T, Lynch DA. Rheumatoid Arthritis-related Lung Diseases: CT Findings 1. Radiology, 2004; 232(1):81-91.

18. Skare TL, Nakano I, Escuissiato DL, Batistetti R, Rodrigues TD, Silva MB. Pulmonary changes on high-resolution computed tomography of patients with rheumatoid arthritis and their association with clinical, demographic, serological and therapeutic variables. Revista brasileira de Reumatologia, 2011; 51(4):331-7.

19. Akira M, Sakatani M, Hara H. Thinsection CT findings in rheumatoid arthritisassociated lung disease: CT patterns and 
their courses. Journal of Computer Assisted Tomography, 1999; 23(6):941-8.

20. Johkoh T, Müller NL, Pickford HA, Hartman TE, Ichikado K, Akira M, Honda O, Nakamura H. Lymphocytic Interstitial Pneumonia: Thin-Section CT Findings in 22 Patients 1. Radiology, 1999; 212(2):567-72.

21. Woodhead F, Wells AU, Desai SR. Pulmonary complications of connective tissue disease. Clin Chest Med, 2008; 29:149-164.
22. Zrour SH, Touzi M, Bejia I, et al.. Correlation between high resolution computed tomography of the chest and clinical function in patients with rheumatoid arthritis. Prospective study in 75 patients. Joint Bone Spine, 2005; 72:41-47.

23. Helmers R, Galvin J, Hunninghake GW. Pulmonary manifestations associated with rheumatoid arthritis. CHEST Journal, 1991; 100(1):235-8.

\section{Source of Support: None Declared} Conflict of Interest: None Declared 